\title{
Gemfibrozil and Nigella Sativa: Comparison
}

\author{
Shah Murad ${ }^{1 *}$, Durreshehwar Marwat ${ }^{2}$, Abdul \\ Qudoos $^{3}$ and M Arif ${ }^{4}$ \\ ${ }^{1}$ Professor of Pharmacology, IMDC, Pakistan \\ ${ }^{2} \mathrm{AP}$ Forensic Medicine at IMDC, Pakistan \\ ${ }^{3}$ Assistant Professor of Pharmacology, FM\&DC, Pakistan \\ ${ }^{4}$ Assoc Professor of FM at IMDC, Pakistan \\ *Corresponding author: Shah Murad, HOD \\ Pharmacology, Islamabad Medical College, Islamabad, \\ Pakistan
}

Received: January 21, 2019; Accepted: February 25, 2019; Published: March 04, 2019

\begin{abstract}
Hyperlipidemia especially LDL-cholesterol may lead to development of coronary artery disease causing morbidity or mortality due to cardiac arrhythmias. Conventional hypolipidemic drugs have unwanted effects. Herbal therapy for Hyperlipidemia is getting attention due to their less frequent side effects. In this study we have compared hypolipidemic effects of Gemfibrozil with Nigella sativa. Seventy five hyperlipidemic patients from Jinnah Hospital Lahore were enrolled for study. After getting consent all patients were divided in three groups comprising 25 patients in each group. Group 1 was on Nigella sativa, group 2 was on Gemfibrozil and third group was on placebo therapy. They were advised to take drugs for two months. After completion of study pretreatment and post treatment values of LDL cholesterol were analyzed statistically. In Nigella sativa group LDL cholesterol decreased from 191.14 \pm 3.45 to $159.40 \pm 2.98 \mathrm{mg} / \mathrm{dl}$, means $31.7 \mathrm{mg} / \mathrm{dl} \mathrm{LDL}$ reduction was observed when compared with placebo group. In Gemfibrozil group of patients LDL cholesterol decreased from $197.77 \pm 3.91 \mathrm{mg} / \mathrm{dl}$ to $159.62 \pm 2.20 \mathrm{mg} / \mathrm{dl}$, means LDL reduction in mean values was $38.2 \mathrm{mg} / \mathrm{dl}$, when compared with placebo group. These changes are highly significant with $p$-values of $<0.001$. We concluded from this study that herbal medicine Nigella sativa is as effective as traditionally used hypolipidemic drug Gemfibrozil.
\end{abstract}

\section{Introduction}

Use of saturated fats cause LDL oxidation in systemic circulation and formation of atherosclerosis and may develop coronary artery disease [1,3-9]. In some cases, a blood clot may totally block the blood supply to the heart muscle, causing heart attack. If a blood vessel to the brain is blocked, usually from a blood clot, an ischemic stroke can result $[2,10]$. Hypolipidemic drugs can be used to treat hyperlidemia, $\mathrm{CAD}$, heart arrhythmias and cardiac arrest. Allopathic drugs used to prevent or cure Hyperlipidemia include Statins, Fibrates, niacin and bile acid binding resins $[3,8]$. Gemfibrozil increases plasma HDL levels by stimulating their synthesis. Increased transport (turnover) of HDL induced by gemfibrozil may be significant in increasing tissue cholesterol removal in hyperlipidemic patients $[4,7]$. Furthermore, Fibrates treatment results in the formation of LDL with a higher affinity for the LDL receptor, which are thus catabolized more rapidly [5-7]. Nigella sativa or kalonji contains conjugated linoleic acid, thymoquinone, melanthin, nigilline, damascenine, and trans-anethole. Thymoquinone (TQ) extracted from Nigella sativa (kalonji) inhibits iron-dependent microsomal lipid peroxidation. Stimulation of polymorph nuclear leukocytes with thymoquinone works as protector against damaging effects of free redicles generated biochemically in human body [10].

\section{Patients and Method}

Research study design was single blind placebo-controlled, and was conducted at Jinnah Hospital, Lahore from February 2012 to July 2012. Seventy five hyperlipidemic patients were selected for research work. Written consent was taken from all patients. Specific Performa was designed for the research work. Seventy-five newly diagnosed primary hyperlipidemic patients were selected with age range from 18 to 70 years. Exclusion criteria were hypothyroidism, diabetes mellitus, alcohol addictive patients, peptic ulcer, any gastrointestinal upset, renal impairment, and any hepatic or cardiac problem. All patients were divided in three groups (group-A, group-B, group-C), 25 in each group. Their baseline experimental data was taken and filed in specifically designed Performa, at start of taking medicine, like lipid profile, blood pressure and pulse rate. The study period was eight weeks. Twenty five patients of group-A were advised to take one tea spoon of Nigella sativa (Kalonji), twice daily, i.e.; one tea spoon after breakfast and one tea spoon after dinner. Twenty-five patients of group-B were advised to take Gemfibrozil $600 \mathrm{mg}$ tablets, one after breakfast and one after dinner. Twenty-five patients were provided placebo capsules, (containing grinded wheat), taking one capsule after breakfast and another before going to bed. All participants were advised to take these medicines for eight weeks. They were also advised for 20 minutes brisk walk at morning or evening time. Patients were called every 2 weeks for follow up to check blood pressure, weight, pulse rate and general appearance of the individual. Drug compliance to the regimen was monitored by interview and counseling at each clinical visits. Serum LDL-cholesterol was calculated by Friedwald formula (LDL-Cholesterol $=$ Total Cholesterol-(Triglycerides $/ 5$ + HDL-Cholesterol). Data were expressed as the mean \pm SD and " $\mathrm{t}$ " test was applied to determine statistical significance as the difference. A probability value of $<0.05$ was considered as non-significancant and $\mathrm{P}<0.001$ was considered as highly significant.

\section{Results}

When results were compiled and statistically analyzed, it was observed that Nigella sativa and Gemfibrozil decreased LDLcholesterol significantly. Nigella sativa decreased LDL cholesterol from $191.14 \pm 3.45 \mathrm{mg} / \mathrm{dl}$ to $159.40 \pm 2.98 \mathrm{mg} / \mathrm{dl}$. This change in mean values was $31.7 \mathrm{mg} / \mathrm{dl}$ with highly significant $\mathrm{p}$-value of $<0.001$ (Table 1). Gemfibrozil decreased LDL cholesterol from $197.77 \pm 3.91 \mathrm{mg} / \mathrm{dl}$ to 
Table 1: Showing Nigella Sativa group's values and significance.

LDL-C at day-0:191.14 \pm 3.45 at day-60: $159.40 \pm 2.98$ (mean change=31.7mg/dl)

P-value $=<0.001$

Table 2: Showing Gemfibrozil group's values and significance.

LDL-C at day-0:197.77 \pm 3.91 at day-60: $159.62 \pm 2.20$ (mean change $=38.2 \mathrm{mg} / \mathrm{dl}$ )

P-value $=<0.001$

Table 3: Showing Placebo group's values and significance.

LDL-C at day-0:163.10 \pm 1.45 at day-60:159.40 \pm 1.77 (mean change $=3.7 \mathrm{mg} / \mathrm{dl})$

P-value $=>0.05$

KEY: LDL-C: Low Density Lipoprotein Cholesterol; all parameters are measured in $\mathrm{mg} / \mathrm{dl}$, P-value $<0.01$ stands for significant change, $\mathrm{P}$-value $>0.05$ stands for nonsignificant change.

$159.62 \pm 2.20 \mathrm{mg} / \mathrm{dl}$. In mean values this change was $38.2 \mathrm{mg} / \mathrm{dl}$ with highly significant $\mathrm{p}$-value of $<0.001$ (Table 2). Placebo group showed LDL cholesterol reduction from $163.10 \pm 1.45 \mathrm{mg} / \mathrm{dl}$ to $159.40 \pm 1.77$ $\mathrm{mg} / \mathrm{dl}$. This change in mean values was $3.7 \mathrm{mg} / \mathrm{dl}$, with non-significant p-value of $>0.05$ (Table 3 ).

\section{Discussion}

From a young age, cholesterol-laden plaque due to increase level of LDL cholesterol can start to deposit in the blood vessel walls. As individual get older, the plaque burden builds up, inflaming the blood vessel walls and raising the risk of blood clots and heart attack. The plaques release chemicals that promote the process of healing but make the inner walls of the blood vessel sticky. Then, other substances, such as inflammatory cells, lipoproteins, and calcium that travel in bloodstream start sticking to the inside of the vessel walls. To escape from victimization of heart attack or heart arrhythmias, blood cholesterol levels must be kept at normal range. Hypolipidemic drugs include Statins, Fibrates, Niacin, and Bile acid binding resins. These drugs have low patient and doctor compliance due to their side effects. So herbal medicine is going to be popular even in western world. Nigella sativa is one of those medicinal herbs, which is used in more than 100 diseases all over the world. In this study, we have compared LDL cholesterol lowering effects of traditional drug Gemfibrozil with medicinal herb Nigella sativa. Nigella sativa when used by 25 hyperlipidemic patients for two months, it reduced LDL cholesterol $31.7 \mathrm{mg} / \mathrm{dl}$. Statistically this change is highly significant Our results match with results of study conducted by N. A. Zeggwagh et al [11] who proved $28.99 \mathrm{mg} / \mathrm{dl}$ reduction in LDL cholesterol in 45 hyperlipidemic patients. Their results support our study results. Change in LDL cholesterol in our results are in contrast with results of study conducted by Han SH et al [12] who proved much less reduction in LDL cholesterol when Nigella sativa was used in 100 hyperlipidemic patients for one month. Reason for this contrast may be due to their large sample size and less exposure of patients to take Nigella sativa for only four weeks. They have also explained mechanism of action of Nigella sativa that how these agents act as antioxidant. Nigella Sativa oil with its potent free radical scavenging properties, inhibits Subarachnoid-Haemorrhage-(SAH-) induced lipid peroxidation of the brain tissue against the reactive hydroxyl, peroxyl, and superoxide radicals. This mechanism is also quoted by F. R. Dehkordi and A. F. Kamkhah [13]. In our study, Gemfibrozil decreased LDL cholesterol $38.2 \mathrm{mg} / \mathrm{dl}$ which is highly significant change when analyzed statistically. These results match with results of study conducted by Vuorio A [14] who observed LDL reduction by $600 \mathrm{mg}$ of Gemfibrozil used by 10 patients for 2 weeks. Their results support our results. They explained five mechanisms that how Fibrates make plasma cholesterol levels at normal range. No: 1, By induction of lipoprotein lipolysis 2. By induction of hepatic Fatty Acid (FA) uptake and reduction of hepatic triglyceride production. 3. by increased removal of LDL particles. 4. By reduction in neutral lipid (cholesteryl ester and triglyceride) exchange between VLDL and HDL may result from decreased plasma levels of Triglyceride Rich Lipoproteins (TRL). 5. By increase in HDL production and stimulation of reverse cholesterol transport. Our results do not match with results of study conducted by Dellavalle RP $[15,16]$ who proved that LDL reduction by Gemfibrozil is not significant if used even for three months. Reason for this contrast may be due to lesser dose of Gemfibrozil ie; $300 \mathrm{mg}$ once daily for three months. In their results LDL cholesterol reduction was only $18.53 \mathrm{mg} / \mathrm{dl}$. Research conducted by Dasgupta $S$ et al proved that if Gemfibrozil is used in therapeutic dose for long-term therapy, it can reduce LDL cholesterol and prevent hyperlipidemic patients from being victimized by CAD, cardiac arrest and cardiac arrhythmias.

\section{Conclusion}

We concluded from this research that patient compliance for hypolipidemic agents of herb origin may be good due to their less intensity and frequency of side effects, as observed and experienced by taking traditional hypolipidemic drug Gemfibrozil.

\section{References}

1. Okamoto $\mathrm{H}$, Kamatani N. Successful treatment with fenofibrate; a peroxisome proliferator activated receptor alpha ligand; for a patient with rheumatoid arthritis. Annals of the rheumatic diseases. 2004; 63: 1002-1003.

2. Abdel-Aal ESM, Attia RS. Characterization of black cumin (Nigella sativa) seeds. Alex Sci Exch. 2011; 14: 483-496.

3. Al-Elyani RAA. Protective effect of honey with Nigella sativa mixture and the ginger on the enoxaparin sodium (anticoagulant drug) hepatotoxicity of albino rats. Umm Al-Qura Uni. J Sci Med Eng. 2008; 20: 39-48.

4. Hossain MA, Tsujita M, Gonzalez FJ, Yokoyama S. Effects of fibrate drugs on expression of ABCA1 and HDL biogenesis in hepatocytes. Journal of cardiovascular pharmacology. 2008; 51: 258-266.

5. Oram JF, Lawn RM. ABCA. The gatekeeper for eliminating excess tissue cholesterol. Journal of lipid research. 2011; 42: 1173-1179.

6. Ahmed KA, Muniandy S, Ismail IS. Role of $\mathrm{N} \varepsilon$-(carboxymethyl) lysine in the development of ischemic heart disease in type 2 diabetes mellitus. J Clin Biochem Nutr. 2007; 41: 97-105.

7. Scharnagl $H$, Nauck $M$, Wieland $H$, Marz W. The Friedewald formula underestimates LDL cholesterol at low concentrations. Clin Chem Lab Med. 2011; 39: 426-428.

8. Md Asaduzzaman Khan, Han-chun Chen, Mousumi Tania, Dian-zheng Zhang. Anticancer activities of Nigella Sativa. Afr J Tradit Complement Altern Med. 2011; 8: 226-232.

9. Assayed ME. Radioprotective effects of black seed (Nigella sativa) oil against hemopoietic damage and immunosuppression in gamma-irradiated rats. Immunopharmacol Immunotoxicol. 2010; 32: 284-296. 
10. Kostapanos MS, Liamis GL, Milionis HJ, Elisaf MS. Do statins beneficially or adversely affect glucose homeostasis? Curr Vasc Pharmacol. 2010; 8: 612 631.

11. Zeggwagh ZA, Moufid A, Khaldi A, Michel ZB, Eddouks M. Cardiovascular effects of Nigella sativa aqueous extract. Circulation. 2010; 6: 343-346.

12. Han SH, Quon MJ, Koh KK. Use of Nigella sativa in Hyperlipidemia. Clinical Pharmacology. 2010; 46: 1086-1092.

13. Dehkordi FR, Kamkhah AF. Antihyperlipidemic effects of Nigella sativa seed extract in patients with primary Hyperlipidemia. Fundamental and Clinical Pharmacology. 2010; 81: 1102-1109.
14. Vuorio A, Kuoppala J, Kovanen PT, Humphries SE, Strandberg T, Tonstad $\mathrm{S}$, et al. Fibrates for familial hypersholesterolemia. Cochrane Database of Systematic Reviews. 2011; 8: 123-127.

15. Dellavalle RP, Nicholas MK, Schilling LM. Role of Fibrates in hypercholesterolemia. American journal of therapeutics. 2008; 10: 203-210.

16. Dasgupta S, Roy A, Jana M, Hartley DM, Pahan K. Gemfibrozil reduces risk of coronary artery disease. Molecular pharmacology. 2007; 72: 934-946.
Austin J Pharmacol Ther - Volume 7 Issue 1 - 2019

ISSN: 2373-6208 | www.austinpublishinggroup.com Murad et al. () All rights are reserved
Citation: Murad S, Marwat D, Qudoos A and Arif M. Gemfibrozil and Nigella Sativa: Comparison. Austin J Pharmacol Ther. 2019; 7(1).1109. 